\title{
Philip F. Stahel and Cyril Mauffrey (Eds.): Patient Safety in Surgery
}

\author{
2014, XV, 513 p, 54 illus., 37 illus. in color. Hardcover: 200,44 $€$-The eBook version of \\ this title will be available soon. Springer-Verlag Paris, Berlin, Heidelberg, New York, \\ Hong Kong, Londres, Milan, Tokyo, ISBN: 978-1-4471-4369-7
}

\section{Pierre Kehr}

Received: 10 September 2014/ Accepted: 15 September 2014/Published online: 24 September 2014

(C) Springer-Verlag France 2014

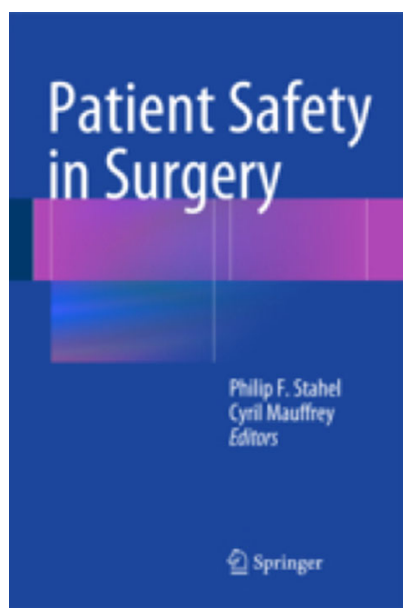

This book constitutes the quintessence of the professional experience of a team of surgeons traumatologists of one of the greatest centers of traumatology of the USA, the Trauma Centers of Denver (CO). As of the introduction, the relationship between the surgeon who wants to save the life and/or the job functions of a wounded patient and the risks of the human nature is very clearly exposed. The incidents and accidents come generally not from a per-operative error, but in consequence of pre- or post-operative errors. The asked questions are as follows: how a patient can be sure that he deals with a qualified and reliable surgeon, how to know if the processing suggested is well the best and best adapted to its case? How finally to know if the surgical team is dominated by an immutable culture of the safety of the patient and a complete adhesion of all her members to the principles of this culture? How the patient can be certain that its case will not enter a learning curve of a new procedure or the training of a young surgeon?

The irony wants that in the USA, the high level of the surgical protocols raises since of the decades of the legal procedures and the action groups of the patients that of an internal regulation of the surgical services. It is time to put an end to this situation. "Patient Safety in Surgery" wants to study with $360^{\circ}$ the safety of the surgical patients.

The work is divided into four great parts:

Part I: General aspects with 20 chapters

Part II: Specific aspects of the surgeon with five chapters

Part III: Other aspects with five chapters

Part IV: Presentation of four clinical cases with each time various scenarios suggested and discussed

The book ends in a conclusion preaching the socket of the therapeutic decisions by a surgical team in full agreement with the patient and his family «nothing for me without me». The authors quote Gene Kranz, director of the Apollolunar mission: we must be tough and competent in all our actions!

A glossary of definitions, a datasheet of the follow-up of the patient, the score and the checklist of the TC of Denver, a broad bibliography for which wants to know more and finally an index making it possible to enter quickly in the middle of the various chapters finishes the book.

True bible of modern traumatology to the USA, this work is actually to regard as a worldwide reference in this field. It will have to appear in good place in the libraries of all the centers of traumatology, but to also be on the desk of all the trainees surgeons, but also seniors, who want to practice a rigorous surgery and with competence near the patients that misfortunes of the life directed towards them.

P. Kehr $(\square)$

Strasbourg, France

e-mail: kehrpier@aol.com 